\title{
Retinal and choroidal thickness in pediatric patients with sickle cell disease: a cross-sectional cohort study
}

\author{
Juliana Prazeres' ${ }^{1}$ Luiz Filipe Lucatto', Adriano Ferreira', Nilva Moraes', Josefina A. P. Braga², Luiz H. Lima',
} Caio Regatieri ${ }^{1}$ and Maurício Maia ${ }^{{ }^{*}}$ (D)

\begin{abstract}
Background: To measure the retinal/choroidal thicknesses in the macular area of asymptomatic pediatric patients with sickle cell disease (SCD).

Methods: This cross-sectional cohort study included 40 children (79 eyes) with SCD and 19 control patients (36 eyes). All subjects underwent spectral-domain optical coherence tomography (SD-OCT) with enhanced-depth imaging OCT. Generalized Estimating Equations (GEE) were applied to compare the outcomes between groups. $P \leq 0.05$ was considered significant.

Results: The choroidal thickness in the macular area in the study subfields was significantly thinner in the SCD eyes compared with control eyes (subfoveal subfield and temporal parafoveal subfield, $p<0.0001$; nasal parafoveal subfield, $p<0.0001$ temporal perifoveal subfield, $p<0.0001$; and nasal perifoveal subfield, $p<0.0001$ ). The variations in the retinal thickness were not significant.
\end{abstract}

Conclusion: EDI-OCT showed that the macular choroidal thickness is thinner in asymptomatic pediatric patients with SCD.

Keywords: Retinal thickness, Choroidal thickness, Sickle cell disease

\section{Background}

Sickle cell disease (SCD) is an autosomal recessive hematologic disease that results from the substitution of glutamic acid by valine in the hemoglobin molecule [1]. Consequently, the hemoglobin solubility changes resulting in chronic hemolysis and vaso-occlusive events. The irregular shape of the red blood cells may lead to blood flow disturbances, chronic hemolytic anemia, and several systemic complications [2].

Visual loss has been reported in $10 \%$ to $20 \%$ of patients with SCD possibly due to clinical manifestations in

\footnotetext{
*Correspondence: maiamauricio@terra.com.br

${ }^{1}$ Department of Ophthalmology, Federal University of São Paulo, 806, Botucatu Street, São Paulo 04026-062, Brazil

Full list of author information is available at the end of the article
}

several parts of the eye, including the conjunctiva, iris, uvea, and retina [1]. A higher prevalence of retinopathy is seen in patients with hemoglobin SC compared to those with hemoglobin SS. Although the retinal findings in SCD are predominantly in the retinal periphery, macular changes also can occur including macular infarctions and enlargement of the foveal avascular zone with perifoveal capillary dropout $[3,4]$.

Previous studies in adults with SCD using spectraldomain optical coherence tomography (SD-OCT) have reported retinal thinning in the macular area due to retinal arteriolar occlusion and decreased choroidal thickness [5-8]. Although the macular findings in adults with SCD have been well described, few studies have specifically assessed the macula in pediatric patients $[9$,

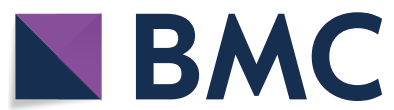

(c) The Author(s) 2022. Open Access This article is licensed under a Creative Commons Attribution 4.0 International License, which permits use, sharing, adaptation, distribution and reproduction in any medium or format, as long as you give appropriate credit to the original author(s) and the source, provide a link to the Creative Commons licence, and indicate if changes were made. The images or other third party material in this article are included in the article's Creative Commons licence, unless indicated otherwise in a credit line to the material. If material is not included in the article's Creative Commons licence and your intended use is not permitted by statutory regulation or exceeds the permitted use, you will need to obtain permission directly from the copyright holder. To view a copy of this licence, visit http://creativecommons.org/licenses/by/4.0/. The Creative Commons Public Domain Dedication waiver (http://creativeco mmons.org/publicdomain/zero/1.0/) applies to the data made available in this article, unless otherwise stated in a credit line to the data. 
10]. These reports showed retinal atrophy with macular thinning and flow voids in both the superficial and deep retinal capillary plexus. The purpose of this study was to analyze the retinal and choroidal thickness measurements in the macular area of asymptomatic pediatric patients with SCD using SD-OCT. To the best of our knowledge, this is the first study to evaluate the choroidal thickness in pediatric patients with SCD.

\section{Methods}

The institutional review board and ethics committee of Federal University of São Paulo, São Paulo, Brazil, approved this study (Ethics Committee Number, $1529 / 11)$, which complied with the tenets of the Declaration of Helsinki.

A retrospective analysis was performed in consecutive asymptomatic pediatric patients with SCD seen in the Department of Ophthalmology of the Federal University of São Paulo, São Paulo, Brazil. The diagnosis of SCD was confirmed by hemoglobin electrophoresis. Patients were excluded who had a best-corrected visual acuity (VA) below 20/20, clinical evidence of maculopathy, epiretinal membranes, a spherical equivalent refractive error exceeding 6 diopters (D) of myopia, amblyopia, lens or vitreous opacity, retinopathy of prematurity, or any systemic condition such as diabetes mellitus, systemic hypertension, or an infectious or autoimmune disease that can cause retinal vascular disease.

All study patients underwent VA measurement using the Snellen chart, slit-lamp biomicroscopy, indirect ophthalmoscopy after pupil dilatation, and fundus photograph (Visucam, Carl Zeiss Meditec, Jena, Germany). The SD-OCT retinal and choroidal images were obtained using the Heidelberg Spectralis (version 1.5.12.0, Heidelberg Engineering, Heidelberg, Germany). Each OCT section was comprised of 100 averaged scans acquired using eye tracking that were taken in a $5 \times 30$-degree rectangle including the optic nerve and macula. In addition to conventional OCT scans, the choroid was imaged with the Heidelberg Spectralis using enhanced-depth imaging (EDI). All OCT scans were obtained between 9:00 and 11:00 am. Two examiners performed the measurements independently, and if the difference between their thickness measurements was higher than $15 \%$ of the mean of two values, a senior author was consulted.

The retinal measurements were performed according to the thickness map with nine Early Treatment Diabetic Retinopathy Study (ETDRS)-like subfields displayed. On the ETDRS map, the macula is divided into nine regions with three concentric rings measuring $1 \mathrm{~mm}$ (innermost ring), $3 \mathrm{~mm}$ (inner ring), and $6 \mathrm{~mm}$ in diameter (outer ring) centered on the fovea. The 1-mm innermost ring is the fovea, and the inner $3-\mathrm{mm}$ ring and outer $6-\mathrm{mm}$ ring were divided further into four equal regions, i.e., the central, parafoveal and perifoveal superior, temporal, inferior, and nasal subfields. The macular volume was recorded from the retinal thickness map.

The horizontal and vertical enhanced-depth imaging EDI-OCT crosshair scans centered on the fovea were analyzed. Choroidal imaging was performed as a single line scan, $7.2 \mathrm{~mm}$ long, passing directly through the foveal center, using the EDI protocol in the Heidelberg machine. The choroidal thickness was measured perpendicularly from the outer edge of the retinal pigment epithelium to the chorioscleral boundary at five points: subfoveal, nasal perifoveal ( $500 \mu \mathrm{m}$ nasal to the fovea), nasal perifoveal $(1000 \mu \mathrm{m}$ nasal to the fovea), temporal perifoveal (500 $\mu \mathrm{m}$ temporal to the fovea), and temporal parafoveal (1000 $\mu \mathrm{m}$ temporal to the fovea) (Fig. 1).

Statistical analysis was performed using the Stata v.14.0 software (Stata Corp., College Station, TX, USA). Frequency tables were used for descriptive analyses. The normality of continuous data was assessed using the Shapiro-Wilk test. The groups were compared in terms of demographic characteristics using the Chi-Square test for categorical variables and the Mann-Whitney test for not normally distributed continuous variables. Considering that individuals contributed with measurements of both eyes, the retinal and choroidal thickness values of those with SCD and controls were compared by Generalized Estimating Equations (GEE) models. $\mathrm{P}<0.05$ was considered statistically significant.

\section{Results}

The study group included 79 eyes of 40 subjects (20 boys, 20 girls; mean age, $10.05 \pm 3.37$ years). Thirty-six eyes of 19 healthy patients comprised the control group. The mean VA was $20 / 20$, and the mean refractive error was $0.50 \mathrm{D}$. Hemoglobin SS was observed in 33 patients (82\%), SC in six patients (15\%), and S-beta thalassemia in one patient (3\%). Among the 40 patients with SCD, retinal findings were observed in 26 eyes (32.9\%), i.e., retinal tortuosity in 20 eyes (25.3\%), retinal arteriolar narrowing in five eyes (6.3\%) and a black sunburst in one eye (1.27\%). No study patients had proliferative SC retinopathy. Table 1 shows the demographic characteristics of the patients in each group.

The subfoveal choroidal thickness was $240.78 \pm 21.27$, and the mean foveal retinal thickness was $256.39 \pm 20.84$. Despite the observation of two patients with retinal thinning in the sickle cell anemia group, we found a statistically significant increase in retinal thickness in the nasal parafovea $(\mathrm{p}=0.026)$, inferior parafovea $(\mathrm{p}=0.011)$, temporal parafovea $(\mathrm{p}=0.036)$ in the sickle cell anemia group compared to the control group. (Table 2, Fig. 2). The choroidal thickness measurements decreased in the 


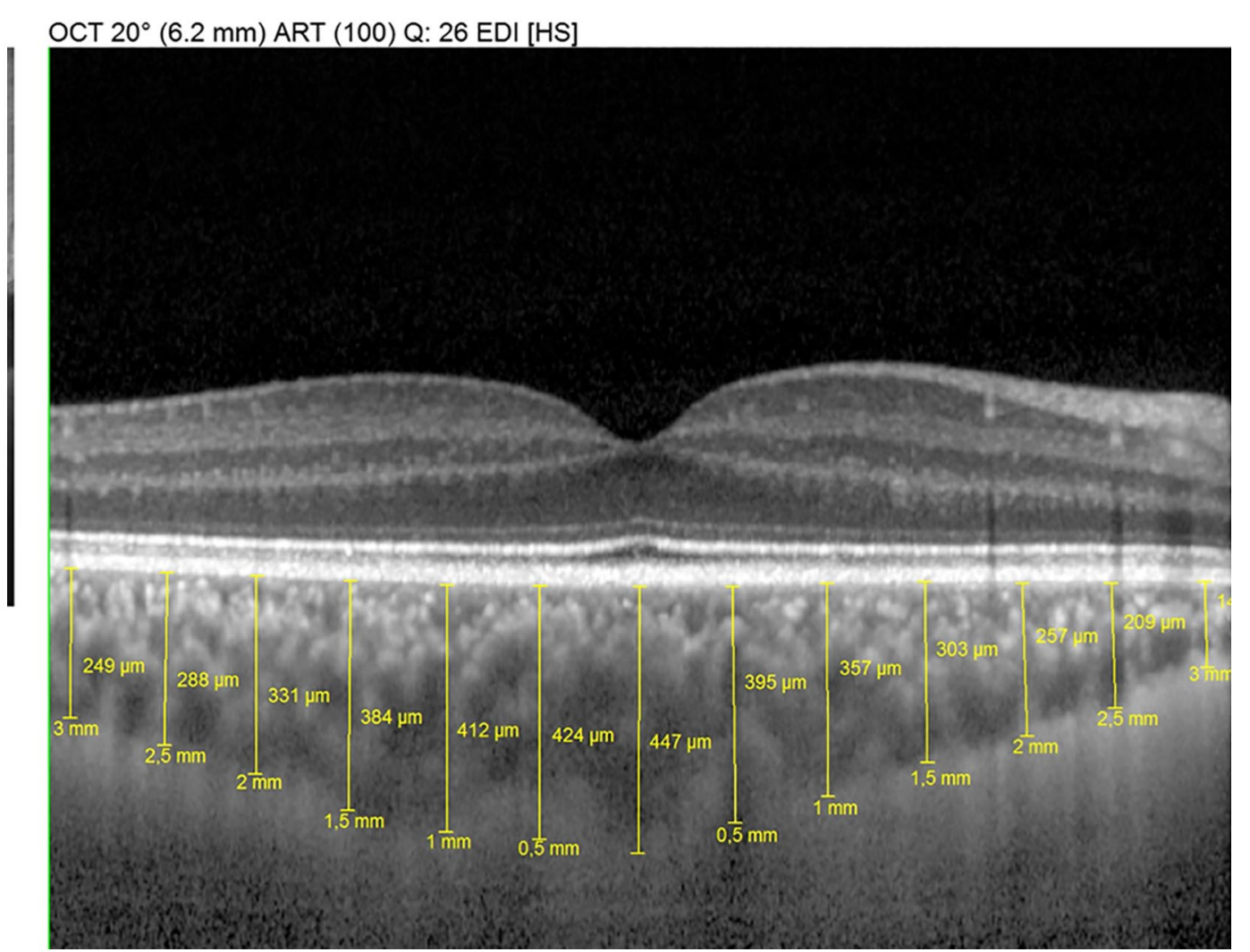

Fig. 1 An EDI-OCT scan from one study patient. The choroidal thickness was measured perpendicularly from the outer edge of the retinal pigment epithelium to the chorioscleral boundary at five points: subfoveal, nasal perifoveal (500 $\mu \mathrm{m}$ nasal to the fovea), nasal perifoveal (1000 $\mu \mathrm{m}$ nasal to the fovea), temporal perifoveal (500 $\mu \mathrm{m}$ temporal to the fovea), and temporal parafoveal (1000 $\mu \mathrm{m}$ temporal to the fovea)

Table 1 Baseline demographic characteristics of children with SCD and control subjects

\begin{tabular}{|c|c|c|c|}
\hline & SCD & Control & $p$ value \\
\hline \multicolumn{4}{|l|}{ Sex, no. (\%) } \\
\hline Male & 20 (50\%) & $10(52.63 \%)$ & 0.850 \\
\hline Female & 20 (50\%) & $9(47.37 \%)$ & \\
\hline $\begin{array}{l}\text { Age, mean } \\
\text { age } \pm \text { standard devia- } \\
\text { tion (median) }\end{array}$ & $10.05 \pm 3.37(9.50)$ & $10.53 \pm 3.82(9.00)$ & 0.7134 \\
\hline
\end{tabular}

SCD eyes. Compared with the control eyes, the choroidal thickness measurements in the SCD eyes decreased in the subfovea $(\mathrm{p}<0.001)$, temporal parafovea $(\mathrm{p}<0.001)$, nasal parafovea $(\mathrm{p}<0.001)$, temporal perifovea $(\mathrm{p}<0.001)$, and nasal perifovea $(\mathrm{p}<0.001)$ (Table 2, Fig. 3 ).

When we analyzed the retinal and choroidal thickness values in the patients with SCD according to the status of the retinopathy, no significant retinal or choroidal thinning was seen in the subgroups (SCD with retinopathy vs. SCD without retinopathy) (Table 3).

\section{Discussion}

Although findings of SC retinopathy are mostly present peripherally, macular changes due to vascular occlusion in SCD have been reported using fluorescein angiography (FA) $[5,11,12]$ electroretinography [13], and histopathology. In the FA studies, the foveal avascular zone was enlarged in patients with SCD. Some studies have reported that macular infarcts can lead to low VA, low foveal sensitivity, and reduced retinal layer thickness on OCT images $[5,6,14]$.

Previous SD-OCT studies in adults with SCD have suggested that areas of macular thinning occur secondary to retinal arteriolar occlusion $[6,7,9]$. More recent studies have reported subclinical central macular thinning, foveal splaying, and focal macular thinning in about $50 \%$ of eyes with SC hemoglobinopathies [6,7]. The studies also suggested that central macular splaying/focal thinning may indicate ischemia attributable to vascular occlusions in the capillaries around the fovea.

Since the choroid is a highly vascularized tissue, it is possible that, as in the retina, a vessel occlusive phenomena can occur at the level of the choroid resulting from 
Table 2 Comparison of SD-OCT retinal and choroidal thickness subfield measurements in the SCD and control groups

\begin{tabular}{llll}
\hline & $\begin{array}{l}\text { SCD } \\
\text { Mean } \boldsymbol{\mu m} \pm \text { standard deviation (median) }\end{array}$ & $\begin{array}{l}\text { Control } \\
\text { Mean } \boldsymbol{\mu m} \pm \text { standard deviation (median) }\end{array}$ \\
\hline $\begin{array}{l}\text { Retinal thickness } \\
\text { Central }\end{array}$ & & & palue \\
Superior parafovea & $256.39 \pm 20.84(256.00)$ & $254.58 \pm 18.89(255.00)$ & 0.748 \\
Nasal parafovea & $344.65 \pm 21.13(344.50)$ & $340.06 \pm 18.80(337.00)$ & 0.378 \\
Inferior parafovea & $345.58 \pm 17.21(343.00)$ & $334.00 \pm 22.24(330.00)$ & $0.026^{*}$ \\
Temporal parafovea & $343.07 \pm 14.80(342.00)$ & $332.28 \pm 18.26(331.50)$ & $0.011^{*}$ \\
Superior perifovea & $330.83 \pm 16.02(331.00)$ & $322.14 \pm 15.89(320.00)$ & $0.036^{*}$ \\
Nasal perifovea & $317.73 \pm 13.24(316.00)$ & $311.18 \pm 21.20(305.00)$ & 0.285 \\
Inferior perifovea & $326.05 \pm 15.06(325.00)$ & $319.75 \pm 19.14(318.50)$ & 0.193 \\
Temporal perifovea & $309.41 \pm 17.15(307.00)$ & $291.60 \pm 23.13(286.00)$ & 0.075 \\
Choroidal thickness & $293.24 \pm 11.09(292.00)$ & $275.87 \pm 41.14(262.50)$ & 0.733 \\
Subfovea & & $266.16 \pm 43.43(255.00)$ & $<0.001^{*}$ \\
Temporal parafovea & $240.78 \pm 21.27(238.00)$ & $251.44 \pm 40.92(236.00)$ & $<0.001^{*}$ \\
Nasal parafovea & $231.08 \pm 21.01(230.00)$ & $247.28 \pm 47.18(228.00)$ & $<0.001^{*}$ \\
Temporal perifovea & $224.52 \pm 17.97(224.00)$ & $220.69 \pm 39.94(214.50)$ & $<0.001^{*}$ \\
Nasal perifovea & $220.15 \pm 30.47(212.00)$ & & $<0.001^{*}$ \\
\hline
\end{tabular}

${ }^{*} p<0.05$ is significant

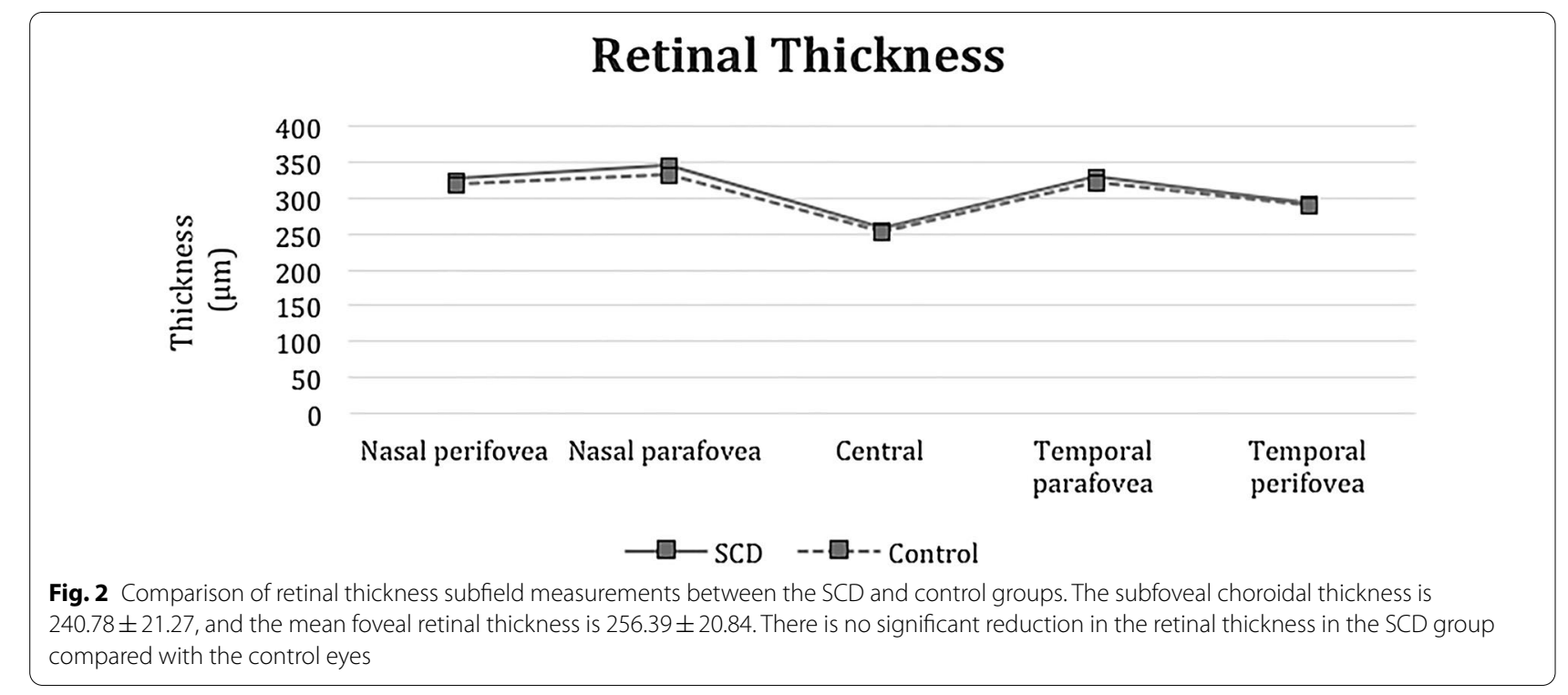

the irregularly shaped red cells. FA, indocyanine green angiography, and ultrasonography do not visualize the choroid completely. Swept-source OCT and EDI-OCT facilitate better visualization of the choroidal anatomy. This noninvasive tool is useful to evaluate the choroidal thickness and indirectly detect choroidal changes in pathologic states such as choroidal capillary non-perfusion due to subclinical embolic events [8]. Mathew et al. [8] reported significant choroidal thinning in adults with $\mathrm{SCD}$ in contrast to discrete areas of retinal thinning. The investigators did not find a correlation between choroidal thinning and areas of macular thinning and suggested that macular microarteriolar occlusions are independent of changes in the choroidal circulation [8].

In the current study, EDI-OCT showed that the macular choroidal thickness is thinner in pediatric patients with SCD. The choroidal thickness in these patients was not correlated with age and was not the normal choroidal thickness seen in the normal control eyes. However, the current study did not identify significant retinal thinning 


\section{Choroidal Thickness}
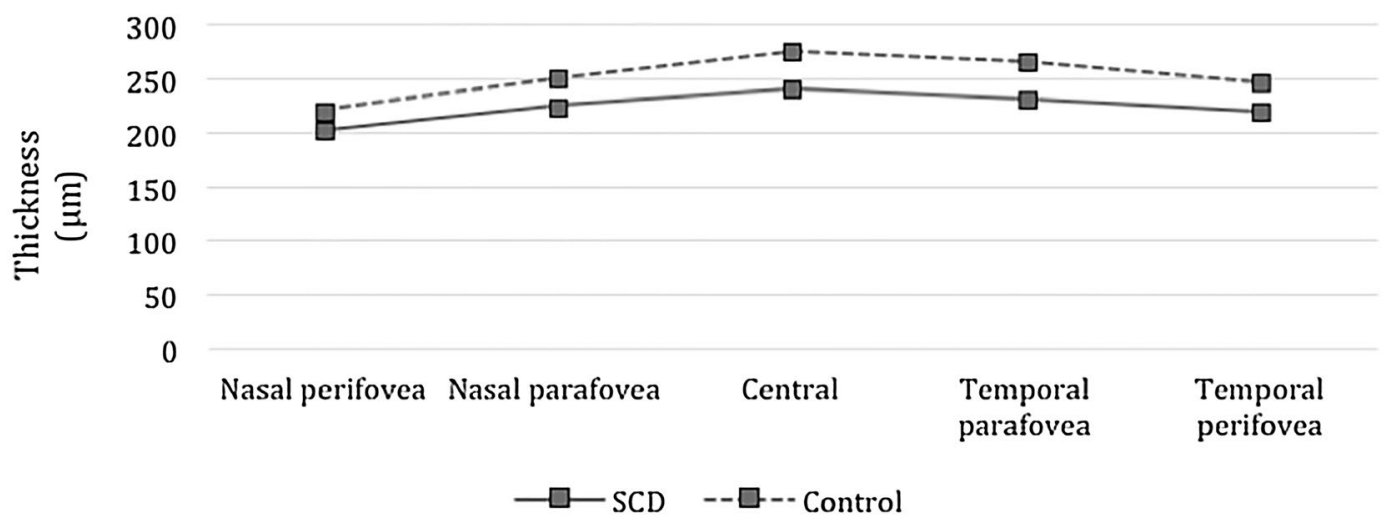

Fig. 3 Comparison of choroidal thickness measurements between the SCD and control groups. The choroidal thickness measurements decreased in the SCD eyes. Compared with the control eyes, the choroidal thickness measurements in the SCD eyes are decreased in the subfovea parafovea $(p<0.001)$ and temporal parafovea $(p<0.001)$, nasal parafovea $(p<0.01)$, temporal perifovea $(p<0.01)$, and nasal perifovea $(p=<0.01)$

Table 3 Comparison of retinal and choroidal thickness measurements using EDI-OCT in patients with SCD with and without retinopathy

\begin{tabular}{|c|c|c|c|}
\hline & $\begin{array}{l}\text { SCD with retinopathy } \\
\text { Mean } \mu \mathrm{m} \pm \text { standard deviation (median) }\end{array}$ & $\begin{array}{l}\text { SCD without retinopathy } \\
\text { Mean } \mu \mathrm{m} \pm \text { standard deviation (median) }\end{array}$ & $p$ value \\
\hline \multicolumn{4}{|l|}{ Retinal thickness } \\
\hline Central & $253.00 \pm 23.39(256.00)$ & $258.15 \pm 19.40(256.00)$ & 0.665 \\
\hline Superior parafovea & $347.48 \pm 30.20(346.00)$ & $343.16 \pm 14.37(344.00)$ & 0.423 \\
\hline Nasal parafovea & $348.52 \pm 22.39(346.00)$ & $344.06 \pm 13.79(343.00)$ & 0.298 \\
\hline Inferior parafovea & $345.26 \pm 19.94(344.00)$ & $341.94 \pm 11.33(341.50)$ & 0.313 \\
\hline Temporal parafovea & $332.11 \pm 18.60(331.00)$ & $330.17 \pm 14.66(329.00)$ & 0.688 \\
\hline Superior perifovea & $323.26 \pm 13.12(320.00)$ & $314.84 \pm 12.49(314.50)$ & $0.029^{*}$ \\
\hline Nasal perifovea & $330.11 \pm 18.58(329.00)$ & $323.94 \pm 12.55(325.00)$ & 0.636 \\
\hline Inferior perifovea & $313.36 \pm 17.04(313.00)$ & $307.26 \pm 17.00(303.50)$ & 0.356 \\
\hline Temporal perifovea & $297.44 \pm 11.97(294.00)$ & $291.06 \pm 10.04(289.00)$ & 0.058 \\
\hline \multicolumn{4}{|l|}{ Choroidal thickness } \\
\hline Fovea & $237.50 \pm 17.86(235.50)$ & $242.46 \pm 22.85(240.00)$ & 0.391 \\
\hline Temporal parafovea & $230.45 \pm 17.18(230.00)$ & $231.41 \pm 22.93(229.00)$ & 0.854 \\
\hline Nasal parafovea & $224.40 \pm 16.03(225.00)$ & $224.59 \pm 19.09(222.00)$ & 0.979 \\
\hline Temporal perifovea & $228.70 \pm 34.87(214.00)$ & $215.77 \pm 27.40(210.00)$ & 0.108 \\
\hline Nasal perifovea & $202.80 \pm 16.62(199.00)$ & $202.13 \pm 18.18(200.00)$ & 0.953 \\
\hline
\end{tabular}

${ }^{*} p<0.05$ is significant

in the nine ETDRS subfields compared with the control group. Retinal thinning was seen in only two patients with SCD. Some authors have reported that the choriocapilar is more sensitive to the effects of hypoxic or ischemic diseases than other ocular components, which may be explained by the lobular arrangement and larger volume of the choroidal vasculature $[8,15]$. Choroidal thinning can occur due to sickling of red blood cells and subsequent reduction in choriocapillar blood flow.
Reports that included both adults and children with SCD showed decreased macular thickness, which was more prominent in the temporal macula. A large series of adults with SCD reported a prevalence of $43 \%$ of eyes with discrete areas of macular thinning on fovea-centered SD-OCT [8]. Martin et al. reported areas of temporal retinal thinning in $38 \%$ of eyes and suggested that retinal thinning may occur early in the disease course [9]. Pahl et al. [10] evaluated 24 eyes of adolescents with 
SCD aged 10 to 19 years and reported macular thinning and flow abnormalities on OCT angiography (OCTA) images. In contrast, Ong et al. observed less dense vasculature on the OCTA images but with similar retinal thickness compared with an age- and race-matched control group and suggested that the microvascular abnormalities may precede the structural retinal thinning [16]. Unlike previous studies, our study showed an increase in retinal thickness in asymptomatic children with sickle cell anemia, which may suggest that retinal thinning occurs at a later stage of the disease.

Despite the normal retinal thickness in the study eyes, we found choroidal thinning in pediatric patients with SCD. Our results suggested that choroidal thinning may precede the retinal thinning in asymptomatic children with SCD, possibly due to the earlier sickling in the choroidal vessels as a result of slower vascular flow.

Ideally, SCD retinopathy should be diagnosed before the proliferative stage develops, since patients may experience visual loss due to macular microinfarcts during the non-proliferative stage. Because patients with SCD begin to exhibit evidence of proliferative retinopathy around 10 years of age, pediatric patients with SCD should be referred to an ophthalmologist as soon as possible [17].

The current study had some limitations. In addition to its retrospective design and small number of study eyes, the choroidal thickness measurements were performed manually. Another limitation is a single choroidal measurement for a constantly changing structure. We performed a single measurement because it is an exam that requires the child's cooperation. To minimize this effect of daily variation, we performed all exams between 9 and $11 \mathrm{am}$.

In conclusion, the current study showed that the choroid was significantly thinner in the macular area of pediatric patients with $\mathrm{SCD}$, which may be related to the choroidal microvasculature changes that precede retinal thinning.

\section{Abbreviations \\ SCD: Sickle cell disease; SD-OCT: Spectral-domain optical coherence tomography; VA: Visual acuity; D: Diopters; ETDRS: Early Treatment Diabetic Retinopathy Study; FA: Fluorescein angiography; EDI-OCT: Enhanced-depth imaging optical coherence tomography; OCTA: Optical coherence tomogra- phy angiography.}

\section{Acknowledgements}

Not applicable.

\section{Authors' contributions}

JP and NM participated in study elaboration, clinical evaluation, interpretation of data, coordination and helped to draft the manuscript. JAPB analyzed and evaluated the patient data regarding sicke cell disease. LFL, AF, CR participated in study design and helped to draft the manuscript. LHL and MM participated in coordination, interpretation of data, study design and helped to draft the manuscript. All authors read and approved the final manuscript.

\section{Funding}

The authors received no financial support for the research, authorship, and/or publication of this article.

\section{Availability of data and materials}

The datasets used and/or analysed during the current study are available from the corresponding author on reasonable request.

\section{Declarations}

\section{Ethics approval and consent to participate}

The institutional review board and ethics committee of Federal University of São Paulo, São Paulo, Brazil, approved this study and all patients parents or legal guardian provided informed consent after adequate study explanation.

\section{Consent for publication}

Not applicable.

\section{Competing interests}

The authors declare that they have no competing interests.

\section{Author details}

'Department of Ophthalmology, Federal University of São Paulo, 806, Botucatu Street, São Paulo 04026-062, Brazil. ${ }^{2}$ Department of Pediatrics, Federal University of São Paulo, São Paulo, Brazil.

Received: 23 June 2021 Accepted: 17 December 2021

Published online: 04 March 2022

\section{References}

1. Fadugbagbe $A O$, Gurgel RQ, Mendonça CQ, Cipolotti R, Dos Santos AM, Cuevas LE. Ocular manifestations of sickle cell disease. Ann Trop Paediatr. 2010;30:19-26.

2. Reynolds SA, Besada E, Winter-Corella C. Retinopathy in patients with sickle cell trait. Optometry. 2007;78:582-7.

3. Moriarty BJ, Acheson RW, Condon PI, Serjeant GR. Patterns of visual loss in untreated sickle cell retinopathy. Eye. 1988;2:330-5.

4. Elagouz M, Jyothi S, Gupta B, Sivaprasad S. Sickle cell disease and the eye: old and new concepts. Surv Ophthalmol. 2010;55:359-77.

5. Witkin AJ, Rogers AH, Ko TH, Fujimoto JG, Schuman JS, Duker JS. Optical coherence tomography demonstration of macular infarction in sickle cell retinopathy. Arch Ophthalmol. 2006;124:746-7.

6. Chow CC, Genead MA, Anastasakis A, Chau FY, Fishman GA, Lim Jl. Structural and functional correlation in sickle cell retinopathy using spectral-domain optical coherence tomography and scanning laser ophthalmoscope microperimetry. Am J Ophthalmol. 2011;152:704-11.

7. Hoang QV, Chau FY, Shahidi M, Lim JI. Central macular splaying and outer retinal thinning in asymptomatic sickle cell patients by spectral-domain optical coherence tomography. Am J Ophthalmol. 2011;151:990-4.

8. Mathew R, Bafiq R, Ramu J, Pearce E, Richardson M, Drasar E, et al. Spectral domain optical coherence tomography in patients with sickle cell disease. Br J Ophthalmol. 2015;99:967-72.

9. Martin GC, Albuisson E, Brousse V, de Montalembert M, Bremond-Gignac D, Robert MP. Paramacular temporal atrophy in sickle cell disease occurs early in childhood. Br J Ophthalmol. 2019;103:906-10.

10. Pahl DA, Green NS, Bhatia M, Lee M, Chang JS, Licuri M, et al. Optical coherence tomography angiography and ultra-widefield fluorescein angiography for early detection of adolescent sickle retinopathy. Am J Ophthalmol. 2017:183:91-8

11. Asdourian GK, Nagpal KC, Busse B, Goldbaum M, Rabb MF, Goldberg MF, et al. Macular and perimacular vascular remodelling sickling haemoglobinopathies. Br J Ophthalmol. 1976;60:431-53.

12. Sanders RJ, Brown GC, Rosenstein RB, Magargal L. Foveal avascular zone diameter and sickle cell disease. Arch Ophthalmol. 1991;109:812-5.

13. Cusick M, Toma HS, Hwang TS, Brown JC, Miller NR, Adams NA. Binasal visual field defects from simultaneous bilateral retinal infarctions in sickle cell disease. Am J Ophthalmol. 2007;143:893-6. 
14. Murthy RK, Grover S, Chalam KV. Temporal macular thinning on spectraldomain optical coherence tomography in proliferative sickle cell retinopathy. Arch Ophthalmol. 2011;129:247-9.

15. Wajer SD, Taomoto M, McLeod DS, McCally RL, Nishiwaki H, Fabry ME, et al. Velocity measurements of normal and sickle red blood cells in the rat retinal and choroidal vasculatures. Microvasc Res. 2000;60:281-93.

16. Ong SS, Linz MO, Li X, Liu TYA, Han IC, Scott AW. Retinal thickness and microvascular changes in children with sickle cell disease evaluated by optical coherence tomography (OCT) and OCT angiography. Am J Ophthalmol. 2020;209:88-98.

17. Babalola OE, Wambebe CO. When should children and young adults with sickle cell disease be referred for eye assessment? Afr J Med Med Sci. 2001;30:261.

\section{Publisher's Note}

Springer Nature remains neutral with regard to jurisdictional claims in published maps and institutional affiliations.

- fast, convenient online submission

- thorough peer review by experienced researchers in your field

- rapid publication on acceptance

- support for research data, including large and complex data types

- gold Open Access which fosters wider collaboration and increased citations

- maximum visibility for your research: over $100 \mathrm{M}$ website views per year

At BMC, research is always in progress.

Learn more biomedcentral.com/submissions 